\title{
LOS ENCUENTROS ENTRE MÉXICO Y LOS ESTADOS UNIDOS EN SPANGLISH Y LOS TRES ENTIERROS DE MELQUIADES ESTRADA
}

\author{
Samuel Manickam
}

\begin{abstract}
RESUMEN
En este artículo se hace un análisis comparativo de la imagen del inmigrante mexicano retratada en dos filmes recientes de Hollywood, Spanglish y Los tres entierros de Melquiades Estrada. Se discuten aspectos como los personajes principales, la relación mexicana-americana y la experiencia bicultural bilingüe, entre otros.

Palabras claves: estereotipo, frontera, trasnacional, hollywoodense.
\end{abstract}

\begin{abstract}
In this article the author carries out a comparative analysis of the representation of the Mexican migrant worker in two recent Hollywood films, Spanglish and The Three Burials of Melquiades Estrada. Aspects such as the main characters, the Mexican-American relationship and the bicultural-bilingual experience, among others will be discussed.

Key words: stereotype, border, transnational, Hollywood.
\end{abstract}

La frontera entre México y los Estados Unidos ha sido una zona geográfica conflictiva y contradictoria a lo largo de la historia de estos países vecinos. Mientras para algunos estadounidenses esta frontera larga representa la línea proverbial en la arena que tiene que ser protegida a todo costo contra las hordas invasoras de mexicanos indocumentados, para muchos mexicanos es un recordatorio humillante de cuán lejos han llegado los "Yankees" para robar lo que era territorio nacional mexicano.

\footnotetext{
Samuel Manickam. Assistant Professor of Spanish. Dept. of Foreing Languages \& Literatures. University of North Texas Correo electrónico: manickam@unt.edu
}

Recepción: 15- 12- 2010

Aceptación: 21- 1- 2010 
Por otra parte, para los inmigrantes mexicanos que anhelan encontrar una vida económica más próspera en el "norte", la frontera representa un reto abrumante que hay que superar. Sin embargo, los estadounidenses en ruta a destinos turísticos como Cancún, Acapulco y Puerto Vallarta no se fijan en el acto de cruzar esta frontera, ya que no necesitan ni visados ni permisos especiales para ingresar a México.

La frontera méxico-estadounidense ha sido un tema constante en los filmes de Hollywood casi desde los principios de esta industria cinemática. Debido a su habilidad refinada por proyectar imágenes duraderas, tanto positivas como negativas, es imposible subestimar el impacto que este cine ha tenido en el público estadounidense respecto a sus percepciones de culturas y grupos étnicos ajenos, sobre todo la cultura mexicana. Carlos E. Cortés acierta cuando nota que los filmes hollywoodenses "[have] provided audiences with an informal, often unintended education on immigration" (1993: 53). Durante la mayor parte de su existencia, Hollywood ha retratado a los mexicanos de manera negativa. El típico personaje mexicano ha sido un bandido violento y malévolo, aun con sus propios paisanos. El término despectivo para referirse a los mexicanos "greaser" fue usado descaradamente en docenas de filmes durante la primera mitad del siglo XX, por ejemplo: "The Greaser's Gauntlet", "The Girl and the Greaser", "Bronco Billy and the Greaser", "The Greaser's Revenge" y "Guns and Greasers" (Pettit 1980: 132).

Observa Cortés que hasta la década de los sesenta los mexicanos en el cine de Hollywood raramente aparecen como personas bien desarrolladas y que, más bien, emergen como peones pasivos sin personalidad para proveer un pretexto para los duelos entre los héroes blancos y los mexicanos maleantes (1993: 65). En las últimas décadas, no obstante, la imagen cinemática del mexicano se ha vuelto más multidimensional y realista que permite hasta mirar con cierta simpatía a los ciudadanos de este país vecino.

En este trabajo, llevaré a cabo un análisis comparativo de dos filmes recientes de Hollywood cuya premisa es la experiencia del mexicano indocumentado en los Estados Unidos: Spanglish (2004), del director James L. Brooks, y Los tres entierros de Melquiades Estrada 1 (2005), del director y actor Tommy Lee Jones. A diferencia de los filmes hollywoodenses de antaño con su imagen racista y limitada del mexicano, estos dos filmes muestran una sensibilidad y simpatía hacia el más grande grupo étnico minoritario en los Estados Unidos, aunque, como se verá, no dejan de proyectar algunos estereotipos limitantes. En las siguientes páginas, analizaré algunos aspectos importantes de estos filmes, tales como la caracterización de los protagonistas mexicanos, los retratos de la cultura mexicana y estadounidense, la relación -tanto platónica como íntima- entre los mexicanos y los estadounidenses, así como la experiencia bicultural y bilingüe de algunos personajes.

Un concepto que delineará mi análisis es el "trasnacionalismo", definido por L. Basch et al., como un proceso en donde los inmigrantes "through their daily life activities and social, economic, and political relations, create social fields that cross national boundaries" (1994: 27). Es decir, al cruzar una frontera internacional y acoplarse a una cultura ajena, uno empieza a volverse un "trasnacional" cuando se da cuenta de que ya no tiene lealtades únicamente hacia una cultura, de manera que el concepto que uno tiene del nacionalismo empieza a quebrarse. Se puede notar este proceso de cambio en algunos personajes en estos filmes. Por otra parte, cada quien experimentará el trasnacionalismo de manera distinta ya que esta experiencia transformadora tendrá asociaciones y significados muy personales para cada individuo. 
En Spanglish, Flor Moreno $^{2}$, la protagonista, es una madre soltera mexicana que cruza la frontera junto con su hija Cristina y acaba en Los Ángeles trabajando como criada en la casa de una familia próspera, los Clasky, en la vecindad exclusiva de Bel Air. En poco tiempo, Flor se vuelve indispensable para esta familia, pues realiza muy bien todas las tareas domésticas. Sin embargo, se crea tensión entre ella y la señora Clasky cuando ésta empieza a ejercer influencia sobre su hija Cristina. Al final, después de una cita romántica, pero sin consecuencias, con el señor Clasky, Flor decide dejar este trabajo bien pagado con tal de retomar control sobre la educación cultural de su hija.

En Tres entierros, el protagonista mexicano es Melquiades, quien llega a un pueblo fronterizo tejano en busca de trabajo y allí se amiga con un estadounidense, Pete, que trabaja en el mismo rancho que él. Un día, mientras Melquiades está trabajando en el rancho, le dispara un patrullero de la frontera, Mike Norton, por accidente. Al averiguar quién mató a su amigo, Pete decide secuestrar a Mike, pues quiere que lo acompañe en un viaje a México para darle un entierro justo al cuerpo de Melquiades.

Aunque los dos filmes tienen lugar en ciudades donde son posibles los encuentros diarios entre los mexicanos y los estadounidenses, esto no quiere decir que exista interés en aprender la lengua y conocer mejor la cultura del otro grupo. Casi todas las escenas en Spanglish tienen lugar en Bel Air, la vecindad exclusiva y mayoritariamente blanca en Los Ángeles, donde el único contacto que los residentes tienen con los latinos es a través de los servicios que éstos les ofrecen.

Nadie en la familia Clasky habla español, aunque a veces los adultos intentan comunicarse con Flor a través de palabras o frases básicas aprendidas en la escuela secundaria. A pesar de que los niños Clasky asisten una escuela particular, aparentemente el español no es una materia importante. Por una parte, el aislamiento lingüístico de la familia Clasky es una premisa sólida para un filme que trata los conflictos y malentendidos típicos en un intercambio intercultural, pero, por otra parte, también es una situación realista ya que hay muchos residentes de Los Ángeles que muestran poco interés en acercarse a la población latina, por no hablar de México que queda cerca. Al mismo tiempo, los mexicanos también tienen sus propias vecindades donde un inmigrante recién llegado se sentirá en casa. Mientras uno se quede dentro de los límites de esta área latina de Los Ángeles, uno no tiene que aprender inglés; sin embargo, a la hora de buscar trabajo fuera del barrio uno tiene que aprender la lengua del Otro, como descubre Flor.

En el pueblo fronterizo de Texas, donde tiene lugar Tres entierros, las dos empresas más importantes tienen que ver con los inmigrantes mexicanos -la patrulla de la frontera y los grandes ranchos-. La mayoría de los residentes son blancos que saben poco de los mexicanos, fuera de los trabajadores en los ranchos y los detenidos por la patrulla. A pesar de la cercanía de la frontera con México, a pocos les interesa profundizar su conocimiento de la cultura o la lengua de este país. Cuando Melquiades aparece un día en un rancho y pide agua para su caballo, los hombres blancos lo miran como si hubiera llegado de otro planeta. Pete le pregunta a Melquiades, en español, de dónde viene, y al ver que hay alguien aquí que habla su lengua, Melquiades está aliviado. En poco tiempo, Pete y Melquiades se vuelven buenos amigos.

De hecho, el elemento central de este filme es la amistad entre estos dos hombres - uno mexicano y el otro estadounidense-. Se sabe poco de Pete, fuera de que es un forastero aislado dentro de su propia sociedad. No tiene ni esposa ni hijos para arraigarlo y su personalidad 
brusca e individualista provoca fricciones entre él y los otros residentes del pueblo. El hecho de que él habla español y seguramente conoce México lo vuelve atípico y tal vez aun sospechoso en este lugar insular. Pete es un trasnacional: una persona que con facilidad puede sustituir el código lingüístico español por el inglés y el código cultural mexicano por el estadounidense. Más allá del hecho de que con Melquiades él comparte una lengua y conoce su cultura, en él, Pete encuentra otro ser humano quien, como él, también es un forastero perdido en este pueblo provincial $^{3}$. Como tal son almas gemelas.

El director desarrolla esta amistad a través de varias escenas claves. Por ejemplo, una vez cuando Pete queda admirado con un caballo que Melquiades acaba de comprar, Melquiades se lo da insistiendo que el caballo tiene el nombre "Pete" grabado en la frente. En otra ocasión, Pete lleva a Melquiades a pasar un rato placentero con "las chicas" en un motel. Una vez cuando están sentados frente a un arroyo Melquiades saca la foto de su familia -tiene esposa y tres hijos- para mostrársela a Pete y decirle que si algo le sucediera, llevara su cuerpo a enterrarlo en Jiménez, su pueblo en México. Sólo los mejores amigos se pueden hacer este tipo de petición. Así, a través de la representación nítida de esta amistad, el director acaba humanizando tanto al inmigrante mexicano como al trabajador campesino estadounidense, y, por lo tanto, va más allá de los estereotipos hollywoodenses del "greaser" mexicano y el vaquero americano. También, esta amistad simboliza las posibilidades de una relación basada en lo que comparten México y los Estados Unidos y no una relación tensa a causa de los recelos históricos y las diferencias.

En cambio, en Spanglish no hay amistades que creen un vínculo entre las comunidades de los mexicanos y los estadounidenses, a pesar del título sugestivo. Aunque Flor se esfuerza en aprender inglés y los Clasky son cálidos con ella y su hija, no se forma una amistad duradera y al final todos se retiran a sus propios enclaves culturales. Por lo normal, los niños saben negociar ágilmente el terreno capcioso entre dos culturas, pero aquí la amistad entre los niños Clasky y Cristina es distante. Si en Tres entierros se muestra la posibilidad de una amistad profunda entre un hombre mexicano y su equivalente estadounidense, entonces en Spanglish se pone mucho hincapié en la fricción antagónica entre las mujeres mexicanas y estadounidenses respecto a sus conceptos de la maternidad. Resulta que en este filme la señora Clasky, Deborah, es una protagonista tan importante como Flor.

De acuerdo con lo que se deduce del filme, Deborah representa a la mujer estadounidense contemporánea; sin embargo, la representación no es muy favorable, pues esta mujer es incompetente tanto en su manejo de la vida familiar como en el orbe de la vida profesional. Es una mujer que no sabe qué quiere en la vida. Desde que fue despedida de su trabajo hace meses, ha hecho un esfuerzo por volverse una ama de casa respetable, pero fracasa y por eso tiene que contratar a Flor para cocinar, limpiar y cuidar a los hijos.

El guión la describe despectivamente como "a cool beauty in her mid thirties [who has] the enormous desire to feel loved that only the seriously hard to love can experience". Como una mujer ansiosa, acomplejada y confundida es difícil de amar. Su forma de correr agresivamente para hacer ejercicio, asustando a los demás en el camino, muestra su deseo de parecer superior cuando la verdad es que sufre de la inseguridad personal. Se esfuerza en mantener una apariencia pulcra, un cuerpo rigurosamente moldeado, ropa de moda, una casa suntuosa y una camioneta enorme. Como madre, se impacienta con sus hijos por no ser tan perfeccionistas como ella - su hijo por no tener las agallas por cantar frente a sus amigos y su hija por tener un cuerpo regordete-. 
En el primer encuentro entre ella y Flor, Deborah se esconde tras gafas oscuras, un sombrero y un parasol, mientras que Flor se sienta cómodamente expuesta bajo las rayos del sol. Mientras las inseguridades profundas de Deborah la mantienen como un ser furtivo en las sombras, la personalidad radiante y libre de conflictos interiores de Flor le permite lucir de manera relajada frente a extraños.

El mensaje patente en Spanglish es que mientras las mujeres estadounidenses se han vuelto conflictivas y se encuentran confundidas respecto a su papel en la sociedad, las mujeres mexicanas siguen siendo centradas, seguras y naturales. Sin embargo, ésta no es una proposición tan halagadora para las mujeres mexicanas cuando uno se percata de que en este filme el director le asigna a Flor los papeles femeninos tradicionales de una sociedad patriarcal.

Flor es una madre idealizada, un "ángel de hogar", que muestra paciencia y comprensión con los hijos de Deborah, mientras realiza todas las tareas domésticas de manera eficaz y con buen ánimo. El cuerpo de Flor se presume de un busto y caderas generosas que la vinculan con el papel tradicional de fertilidad femenina, a diferencia del cuerpo sobrecondicionado y delgado de Deborah. El cuerpo voluptuoso de Flor ha producido una hija, Cristina, cuya belleza le hace a Deborah exclamar "You could make a fortune at surrogate pregnancy", revelando así su avaricia capitalista. Deborah empieza a ponerle más atención a Cristina que a sus hijos. La lleva de compras, la inscribe en una escuela particular y le regala joyería -todo sin el permiso de Flor-. Flor se asusta cuando observa que su hija está siendo influenciada por esta mujer estadounidense que no sólo puede ofrecerle a Cristina más en lo material sino que, de importancia clave, puede acabar transformando a su hija en una niña "gringa" que perderá el respeto por su herencia cultural mexicana.

Cristina representa la situación clásica de una trasnacional que se encuentra flotando a la deriva entre su cultura nativa pero distante (México) y la cultura extranjera (Estados Unidos) en que vive. Como asevera Basch et al., "by living their lives across borders, [transnationals] find themselves confronted with and engaged in the nation-building processes of two or more nations" (1994: 34). Cristina tiene que lidiar con las expectativas de dos culturas a la vez, sin embargo, como la niña está atravesando por una etapa formativa de su vida, el acto de negociar con una cultura y lengua nueva le viene más naturalmente, a diferencia de su madre para quien, como una adulta ya lingüísticamente y culturalmente moldeada, le resulta una experiencia desconcertante. Presenciar en su hija las huellas de esta cultura extranjera -por ejemplo, Cristina empieza a hablar con su madre más en inglés que en español- le asusta. A pesar de su rebelión inicial contra su madre y la cultura que representa, al final Cristina acepta su herencia mexicana al decir "I am my mother's daughter". Cristina representa el grupo creciente de méxico-americanos biculturales y bilingües que están cambiando la demografía de los Estados Unidos donde las reglas de "English only" pronto serán caducas. En este sentido, Cristina resulta ser la verdadera protagonista de Spanglish.

Mientras en Spanglish, Cristina cruza la frontera para incursionar en los Estados Unidos durante una etapa formativa e impresionable de su vida y acaba volviéndose una trasnacional que está cómoda con dos culturas a la vez, en Tres entierros, observamos qué le sucede a un patrullero estadounidense de la frontera cuando hace un viaje a México -aunque a fuerza- para conocer este país vecino por la primera vez. Resulta ser una experiencia transformadora de parte-aguas para este hombre que provoca sólo antipatía al principio del filme.

Mike Norton, el hombre al quien Pete obliga a cruzar la frontera, tiene ojos azules que miran fríamente al mundo, acompañado por el ceño siempre fruncido. Es cortante en 
su trato con la gente, ya sea su jefe o un vendedor de casas. No muestra cariño a su joven esposa y en una escena la fuerza a tener relaciones sexuales con él en la cocina mientras ella está cocinando. Como patrullero de la frontera, muestra demasiado afán en detener a los inmigrantes, pues una vez apresa a una pareja intentando a escaparse y golpea a la mujer en la nariz rompiéndosela.

Es evidente su falta de juicio el día que mata a Melquiades por accidente, pues empieza a disparar sin fijarse en quién puede estar disparando hacia él y por qué. Aunque no mató a Melquiades intencionalmente, decide tirar el cuerpo en medio del campo y no decirle nada a nadie, y así se vuelve un criminal. Por lo tanto, cuando Pete secuestra a Mike para que lo acompañe a México donde enterrarán a Melquiades, este acto de venganza parece un castigo justo. En un gesto simbólico, Mike tiene que vestirse con la ropa de Melquiades. Así, al atravesar el desierto donde se quema bajo el sol sin piedad y jadea con sed, Mike pasa por la misma experiencia brutal de Melquiades y muchos otros inmigrantes cuando intentan entrar a los Estados Unidos. Una vez Mike salta de su caballo y huye corriendo descalzo en la arena caliente, pero no llega muy lejos ya que Pete lo persigue y lo captura como si fuera un animal. Para colmo, una víbora de cascabel muerde a Mike, dejándolo discapacitado. Si antes él era el perseguidor, ahora es el perseguido.

En un momento repleto de ironía, Pete tiene que pedir la ayuda de algunos inmigrantes mexicanos para cruzar la frontera a México; ahora es el estadounidense que intenta entrar ilegalmente a México. Otra vez Mike intenta huir pero Pete lo captura con un lazo experto y lo lleva arrastrando por el Río Bravo y de esta manera, Mike llega a México literalmente como un "mojado". En otra vuelta irónica, la curandera que atiende el pie herido de Mike es la misma mujer a quien le había roto la nariz cuando intentaba entrar a los Estados Unidos. Una vez sanado Mike se sienta con la curandera y su familia a deshojar el maíz; esta familia mexicana le ha perdonado y ahora lo acepta como un compañero en un rito tradicional.

Luego, en su viaje, se encuentran con unos hombres en el camino que les regalan carne fresca de oso y una botella de tequila para "las penas" de Mike. De nuevo, se nota la bondad espontánea de los mexicanos hacia estos extranjeros. Cuando por fin encuentran el lugar tranquilo donde creen que Melquiades quería ser enterrado, a Mike le toca cavar el hoyo con piedras y palos en la tierra seca. En un último acto de penitencia, Mike tiene que hincarse frente a la foto de Melquiades para pedirle perdón. Cuando Mike rompe a llorar, sabemos que son lágrimas sinceras que este viaje largo y duro han provocado. Así, si al principio del filme Mike parece un hombre antipático y egoísta que desprecia a los mexicanos, al final vemos a un Mike transformado que de ahora en adelante tratará a los mexicanos con más comprensión. Debido a su duro proceso de aprendizaje en este viaje, Mike ha sido humanizado. También, se ha vuelto un trasnacional, como Pete, para quien la frontera no es una línea estricta y permanente que protege a los ciudadanos de los Estados Unidos contra los intrusos mexicanos sino, más bien, como una línea arbitraria que divide dos pueblos que, a pesar de sus claras diferencias culturales, también comparten muchas cualidades positivas y humanas.

Si por una parte estos filmes hacen aportes novedosos al desarrollar personajes trasnacionales como Cristina y Mike, por otra parte, son menos atrevidos en desarrollar las posibilidades de una relación íntima entre los mexicanos y los estadounidenses. En este aspecto, no difieren completamente del molde establecido por la cultura cinemática hollywoodense que dicta que las relaciones interétnicas no tendrán éxito porque, como nota 
Robyn Wiegman, "the democratic ideal of the 'melting-pot' brings into crisis the relationship between separatist cultures, languages, and sexual activity and the full force of integration which would reconfigure the family and romance along with national identity" (2000: 161).

El dominio del romance de la familia nacional blanca no puede ser amenazado ni por las fantasías cinematográficas producidas por Hollywood. Cortés observa que en este cine el matrimonio entre miembros de grupos étnicos minoritarios y blancos es un tabú y que cuando "such relationships did occur, they almost inevitably ended in tragedy" (1993: 58). En Spanglish, presenciamos la relación romántica en ciernes entre Flor y el señor Clasky, John, que está consumada una noche. Aunque John le dice a Flor que es "a great and wild mother", y ella le dice que es un "beautiful father", estos padres dotados con cualidades ideales no tienen futuro ya que estarían violando las restricciones impuestas por la sociedad. Flor vuelve a su vecindad mexicana en Los Ángeles determinada a proteger a su hija de las influencias corrompedoras de la sociedad estadounidense, mientras que John regresa a Bel Air para intentar arreglar su matrimonio. Así, cualquier posibilidad de una relación amorosa entre una mexicana y un estadounidense queda truncada rápidamente.

En Tres entierros, Pete arregla una cita para él y Melquiades con dos mujeres en un motel. La mujer con quien va Melquiades es Lou Ann Norton quien, por coincidencia, es la esposa de Mike. Como ella está aburrida en este pueblo lejos de su casa y se siente ignorada por su esposo, decide buscar una aventura sexual con un extraño. Es un encuentro íntimo que sólo dura un par de horas. Debido a que ninguno de los habla la lengua del otro y como los dos son tímidos, al principio hay un silencio incómodo. Pero, se rompe el hielo cuando Lou Ann prende el radio y se ponen a bailar. Es un encuentro tierno donde estas dos personas solas pueden olvidarse de su soledad brevemente antes de que sus vidas tomen rumbos distintos: la misma tarde Melquiades quedará muerto por los disparos accidentales de Mike y luego Lou Ann abandonará a su esposo para regresar a su casa en Ohio. Ninguna de estas dos relaciones interétnicas ofrece mucha esperanza debido a las diferencias culturales, sociales y económicas, así que tienen que fracasar. También, el hecho de que las dos relaciones son ilícitas las vuelve moralmente sospechosas. Con tales premisas limitantes y tradicionales, los dos directores recaen en las narrativas maestras típicas de Hollywood.

Al fin y al cabo tanto Spanglish como Los tres entierros de Melquiades Estrada muestran cuán diferentes son la cultura mexicana y la estadounidense, a pesar del hecho de que son países vecinos. Si la lengua es una faceta íntegra de la cultura, entonces la inhabilidad de hablar la lengua del Otro cierra la puerta de acceso a su cultura también, como algunos personajes en estos dos filmes descubren. Los Clasky nunca aprenderán el español y Flor siempre verá la cultura estadounidense con recelo. No obstante, los cineastas abren una pequeña brecha en la interpretación de los papeles tradicionales al colocar personajes trasnacionales en estos filmes, como Cristina, Pete y Mike, mostrando así que es posible la comprensión entre estas dos culturas en las que existe tanta desconfianza histórica. Mientras que la adolescente Cristina luce como una representante de la sociedad estadounidense futura (que ya está presente) donde ser bilingüe y bicultural será lo normal, la transformación efectuada en Mike, un adulto monolingüe y conservador, es prueba de que nunca es demasiado tarde para ensanchar las experiencias culturales de uno. En este aspecto, Tres entierros va más lejos al incursionar en nuevo territorio cinematográfico para un filme de Hollywood. 


\section{Notas}

1. De manera bilingüe, este filme tiene títulos tanto en ingles (The Three Burials of Melquiades Estrada) como en español y los personajes hablan en su lengua nativa, que sea ingles o español. En este trabajo, sólo se usará el título español.

2. Debido a que aquí se analizan dos textos fílmicos, vale comentar sobre los actores que realizan los papeles de los protagonistas mexicanos. Mientras Julio Cedillo, el actor estadounidense que toma el papel de Melquiades, nos parece un mexicano creíble por su aspecto físico y acento norteño, la actriz española que toma el papel de Flor, Paz Vega, no convence. Tanto las señales lingüísticas como las culturales marcan claramente el origen español de Paz Vega; como actriz no sabe aparentar siquiera un acento que podría parecer mexicano. Este aspecto divisorio de Flor - una supuesta mexicana que no obstante habla con las inflexiones y el acento de una española -molesta en un filme donde se supone que el enfoque es la lucha de una migrante mexicana en los Estados Unidos-. El hecho de que Paz Vega como actriz no salga (o no tenga que salir) de su piel española en este filme se vuelve una distracción y hace cuestionar la seriedad del director como para tratar el tema de la inmigración mexicana. También, el hecho de que el guión exige "a drop-dead gorgeous latin woman in her early twenties" en el papel de Flor es una clara indicación de las intenciones verdaderas de este director, pues importa más la manera en que esta latina/ española/mexicana (escoja una) mujer se vuelve una distracción y atracción física para el señor Clasky.

3. Todos los personajes en Tres entierros están acechados por la soledad y la enajenación: Pete se siente como un forastero en su propia sociedad, Lou Ann se siente como una extraña en Texas y anhela regresar a Ohio, Melquiades fabrica una familia ficticia en México para sentirse vinculado y Mike es incapaz de llevar a cabo una conversación extendida con cualquier persona.

\section{Bibliografía}

Basch, L., N. Glick Schiller and C. Szanton-Blanc. 1994. Nations unbound: trasnational projects, postcolonial predicaments and deterritorialized nation-states. Langhorne: Gordon \& Breach.

Brent Toplin, Robert. 1993. Hollywood as Mirror: Changing Views of "Outsiders" and "Enemies" in American Movies. Westport: Greenwood Press.

Brooks, James L. 2004. Spanglish script. (Included with DVD).

Cortés, Carlos E. 1993. "Them and Us: Immigration as Societal Barometer and Social Educator in American Film.” En Robert Brent Toplin (ed.), 53-74.

Pettit, Arthur G. Images of the Mexican American in Fiction and Film. College Station: Texas A\&M UP, 1980.

Wiegman, Robyn. 2000. Race, ethnicity and film. En: Hill and Church (eds.), 156-166. 